\title{
Catalytic Stereodivergent Synthesis of Steroid-Fulleropyrrolidine Hybrids
}

Margarita Suárez, ${ }^{\dagger *}$ Alberto Ruiz, ${ }^{\dagger}$ Luis Almagro, ${ }^{\dagger}$ Julieta Coro, $^{\dagger}$ Enrique E. Maroto, ${ }^{\S}$ Salvatore Filipone, ${ }^{\S}$ Dolores Molero, ${ }^{ \pm}$Roberto Martínez-Álvarez, ${ }^{\S}$ Nazario Martín ${ }^{\S *}$

†Laboratorio de Síntesis Orgánica, Facultad de Química, Universidad de la Habana, 10400 La Habana, Cuba.

${ }^{\S}$ Departamento de Química Orgánica I, Facultad de Ciencias Químicas, Universidad Complutense de Madrid, 28040 Madrid, Spain.

${ }^{ \pm}$CAI RMN Universidad Complutense de Madrid, 28040 Madrid, Spain.

E-mail: msuarez@fq.uh.cu, nazmar@quim.ucm.es

This work is dedicated to the memory of Prof. Dr. José L. Mola Gárate

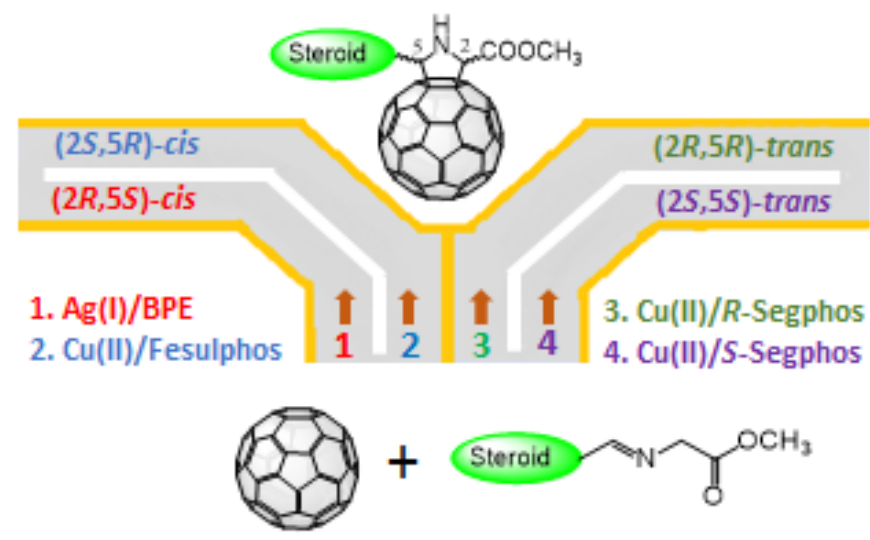

\section{ABSTRACT}

The diastereoselective synthesis of cis and trans steroid-fulleropyrrolidines hybrids by reaction of $N$-metalated azomethine ylides [Cu(II) or $\mathrm{Ag}(\mathrm{I})$ ] with the appropriate chiral ligand and $\mathrm{C}_{60}$ is described. The experimental findings reveal that the azomethine ylide stabilized by an allylic group cycloadds to [60]fullerene in an efficient manner and with a good diastereomeric excess. Furthermore, the new generated stereocenters are fully controlled by the catalytic systems used without being influenced by the chirality of the steroid. Interestingly, by this synthetic methodology the each one of the four possible stereoisomers have efficiently been obtained and characterized by CD spectra.

\section{INTRODUCTION}

The use of fullerenes for bio-medical applications is still an underdeveloped research area. ${ }^{1}$ Therefore, synthetic approaches towards fullerenes covalently bonded to natural 
products are of interest. ${ }^{2}$ On the other hand, it is well known that steroids are biologically relevant molecules showing bio-medical applications. ${ }^{3,4}$ In this regard, conjugating steroids to fullerenes is a topic that has not been properly addressed so far that can lead to interesting molecules with different biological properties. ${ }^{5-11}$

In previous work we have carried out the synthesis of new [60]fullerene-steroid hybrids following the Bingel-Hirsch methodology using cholesterol, $\beta$-sitosterol, and ergosterol as steroid moiety, affording a variety of methanofullerene conjugates exhibiting solubility in different organic solvents, thus obtaining promising functional chimeras with potential biomedical applications. ${ }^{12}$ Soon afterwards, we synthesized new molecular hybrids steroid-fullerenes, using the Prato's procedure by 1,3-cycloaddition of the corresponding formyl-steroid, sarcosine and $\mathrm{C}_{60}$. In that case, we have selected the naturally occurring steroid epiandrosterone, which was conveniently functionalized. This reaction gives rise to the formation of diastereoisomeric mixture of fulleropyrrolidines with poor selectivity due to the generation of a new stereogenic center in the cyclization process. ${ }^{13}$ Recently, we have described the multistep preparation of a fullerene hybrid dumbbell endowed with two fullerene units connected through an epiandrosterone molecule. Suitably functionalized epiandrosterone required a previous chemical modification to introduce a formyl and a malonate groups for further covalent connectivity to the $\mathrm{C}_{60}$ units, first by 1,3 -cycloaddition and then by a cyclopropanation reaction. ${ }^{14}$ In both cases the lack of asymmetric control on the new generated chiral centers gave stereoisomeric mixture.

On the other hand, chirality in fullerenes has recently received a lot of attention because of its importance for preparing optically active compounds for potential use in medicinal chemistry as well as in materials science.

The first successful methodology for obtaining pyrrolidinofullerenes with controlled stereochemistry was described by Martin's group in 2009 using different copper and silver salts and chiral ligands. ${ }^{15}$ This procedure paved the way to the preparation of new and versatile chiral fullerenes at will. Particularly, chiral metal complexes described proved to be versatile catalysts affording optically pure pyrrolidinofullerenes by a fully stereodivergent cycloaddition of azomethine ylides. ${ }^{16}$

Taking into account these aforementioned results, we have carried out a thorough and systematic study to expand the scope of this highly versatile stereoselective catalytic cycloaddition onto $\mathrm{C}_{60}$ to other catalysts and dipoles, reporting a fully stereodivergent methodology for the synthesis of chiral pyrrolidinofullerenes by the correct choice of a 
wide and easily available collection of chiral ligands, metals, and iminoesters or iminoamides. ${ }^{17}$

The aforementioned results achieved in chiral fullerenes were reported in a comprehensive review published in $2014 .{ }^{18}$ All these outcomes pave the way to obtaining enantiomerically pure fullerenes and, therefore, to their use not only in biomedical applications, where chirality is an important issue, but also in materials science, where fullerenes find their main applications.

With the aim to prepare steroid-fullerene hybrids with a controlled stereochemistry, here we report on the stereoselective 1,3-dipolar cycloaddition of steroid $N$-metalated azometine ylides to $\mathrm{C}_{60}$ using a suitable combination of chiral ligand and metal salts, at low temperature, affording each one of the four possible stereoisomers in good yields and high diasteromeric excess, surpassing de values of $93 \%$.

\section{RESULTS AND DISCUSSION}

The stereoselective synthesis of steroid-fullerene hybrids from the 1,3-dipolar cycloaddition of the imine 2 onto $\mathrm{C}_{60}$ has been studied by the application of metal mediated asymmetric catalysis. Since in this process the configuration of the stereogenic centers of the steroid ( $3^{\prime} S, 5^{\prime} S, 8^{\prime} R, 9^{\prime} S, 10 ' S, 14 ' S$ ) does not change during the course of the reaction, a mixture of up to four optically pure stereoisomer could arise from a no controlled formation of the two new formed stereogenic carbon atoms C2 and C5: (2R, $5 R),(2 S, 5 S),(2 S, 5 R)$ and $(2 R, 5 S)$.

The synthesis of the target compounds began with the generation of the imine 2 by mixing the previously reported ${ }^{13} 3$-chloro-2-formyl-17-oxo-5 $\alpha$-androstan-2-ene (1) and glycine methyl ester hydrochloride in the presence of triethylamine using dichlorometane as solvent at room temperature (See Scheme 1). This compound was obtained as a yellow oil in $77 \%$ yield.

The ${ }^{1} \mathrm{H}$ NMR spectrum of 2 shows the disappearance of the signal corresponding to the proton of the formyl group at $\sim 10 \mathrm{ppm}$ and the presence of a signal at $8.22 \mathrm{ppm}$ assigned to the imine proton. In the ${ }^{13} \mathrm{C}$ NMR spectrum appears signals at $170.6 \mathrm{ppm}(\mathrm{O}-$ $\mathrm{C}=\mathrm{O}$ ) and other at $160.7 \mathrm{ppm}$ assigned to the carbon of the imine group. The structure of the compound was ascertained by mass spectrometry. The ESI-MS spectrum for compound 2 shows a peak at $m / z=472.3$ which corresponds to $[\mathrm{M}+\mathrm{Na}]^{+}$, thus supporting the proposed structure. 
The use of anhydrous silver acetate along with an achiral ligand [dppe, 1,2bis(diphenylphosphino)ethane] in toluene at room temperature limits the mixture composition to the two cis-diastereomers $\mathbf{3}$ and $\mathbf{4}$ as indicated by the appearance of two peaks at 6.96 and 10.71 minutes, respectively, in the HPLC chromatogram of the reaction. It is important to note, however, that the stabilization of the $\mathrm{N}$-metalated azomethine ylide is provided by the allylic moiety of the steroid unit, thus resembling the benzylic one (moiety) in previous examples from literature. ${ }^{15}$

The two monoadducts were separated by flash chromatography initially with carbon disulfide, to elute unreacted $\mathrm{C}_{60}$, followed by dichloromethane and dicloromethane: ethyl acetate (100:1) to obtain compounds 3 and 4, in 32\% and 25\% yield, respectively, (Table 1, entry 1) see Scheme 1 . These values show a modest stereoselectivity, as result of the poor chiral induction of the steroid moiety on the attack to one of the faces of the dipole in the fullerene derivative.

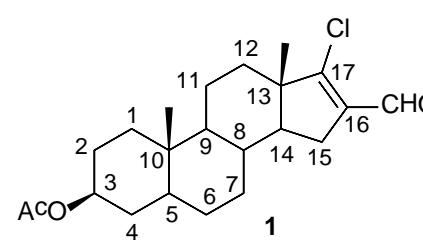

(3S' 5S' 8R' 9S' 10S' 14S)

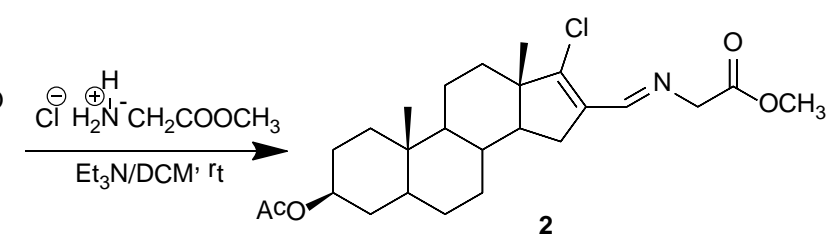

AgOAC/dppe $\mathrm{C}_{60} /$ toluene, $\mathrm{rt}_{\mathrm{t}}$

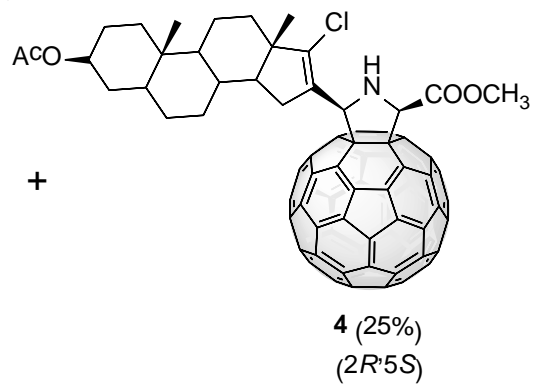

Scheme 1. Synthesis of cis diasteromers of fulleropyrrolidine-steroids hybrids.

Monoaducts $\mathbf{3}$ and $\mathbf{4}$ were fully characterized by analytical and spectroscopic techniques (see the Experimental Section and Supporting Information). ${ }^{1} \mathrm{H}$ NMR spectroscopy revealed the formation of compounds $\mathbf{3}$ and $\mathbf{4}$. Besides the disappearance of the methylene protons ( $\delta=4.31 \mathrm{ppm}$ ) present in 2 , the spectra of compounds 3 and $\mathbf{4}$ show the signals corresponding to the protons of the pyrrolidine ring at $5.57 \mathrm{ppm}(\mathrm{H} 2)$ and 5.81 ppm (H5) for 3 and 5.58 ppm (H2) and 5.86 ppm (H5) for 4. 
The number of signals observed in the ${ }^{13} \mathrm{C}$ NMR spectra between $156 \mathrm{ppm}$ and 136 ppm reveal the lack of symmetry in the fullerene cage in these compounds. The ${ }^{13} \mathrm{C} N \mathrm{NM}$ spectra show, for both 3 and 4, the presence of the fulleropyrrolidine ring on the 6,6-ring junction of the $\mathrm{C}_{60}$ framework at $\sim 77 \mathrm{ppm}$ and $\sim 79 \mathrm{ppm}$, and those corresponding to the carbons of the fulleropyrrolidine ring appear at $\sim 73 \mathrm{ppm}$ (C2) and $\sim 70 \mathrm{ppm}$ (C5).

HRMS verified the proposed structure. MALDI-TOF spectrum for compound 3, registered in the negative mode of detection, shows a peak at $\mathrm{m} / \mathrm{z}=1169.2330$, corresponding to the odd-electron molecular ion $\mathrm{M}^{0^{-}}$, while the MALDI-TOF spectrum, in positive mode of detection, for compound 4 shows a peak in $\mathrm{m} / \mathrm{z}=1192.2223$ corresponding to $[\mathrm{M}+\mathrm{Na}]^{+}$. (See Experimental Section and Supporting Information).

In order to determine the spatial arrangement of the protons attached to carbons C2 and C5, NOE experiments were performed on both diastereoisomers $\mathbf{3}$ and $\mathbf{4}$. (See Supporting Information Figure S7 and S19, respectively). In both cases, NOE effect was observed showing the spatial proximity of $\mathrm{H} 2$ and $\mathrm{H} 5$ protons, indicating the cis arrangement in both diastereomers.

With the aim of assigning the absolute stereochemistry of the new stereogenic centers formed in the reaction, namely C2 and C5 of the pyrrolidine ring, we registered the CD spectra of both 3 and 4, (see Figure 1). The CD spectra do not present an exactly mirror relationship as expected for two diastereomers. However, inspection of the region around $430 \mathrm{~nm}$, considered as the finger print for every fullerene monoadductus, features peaks with opposite sign corresponding to opposite configurations at the new formed stereogenic centers (Figure 1). Indeed, by using the sector rule, ${ }^{19}$ proposed for fullerene derivatives, ${ }^{13-15}$ which links the Cotton effect (CE) associated with this UV-vis band and the stereochemical environment around the 6,6 junction, we could assign the configuration of both $\mathrm{C} 2$ and $\mathrm{C} 5$ atoms.

Compound 3-cis showed in its CD spectrum a positive CE, which is consistent with a $(2 S, 5 R)$ stereochemistry (Figure 1 , a). The negative CE observed in the CD spectrum of 4-cis, indicates a $(2 R, 5 S)$ configuration (Figure 1, b). 

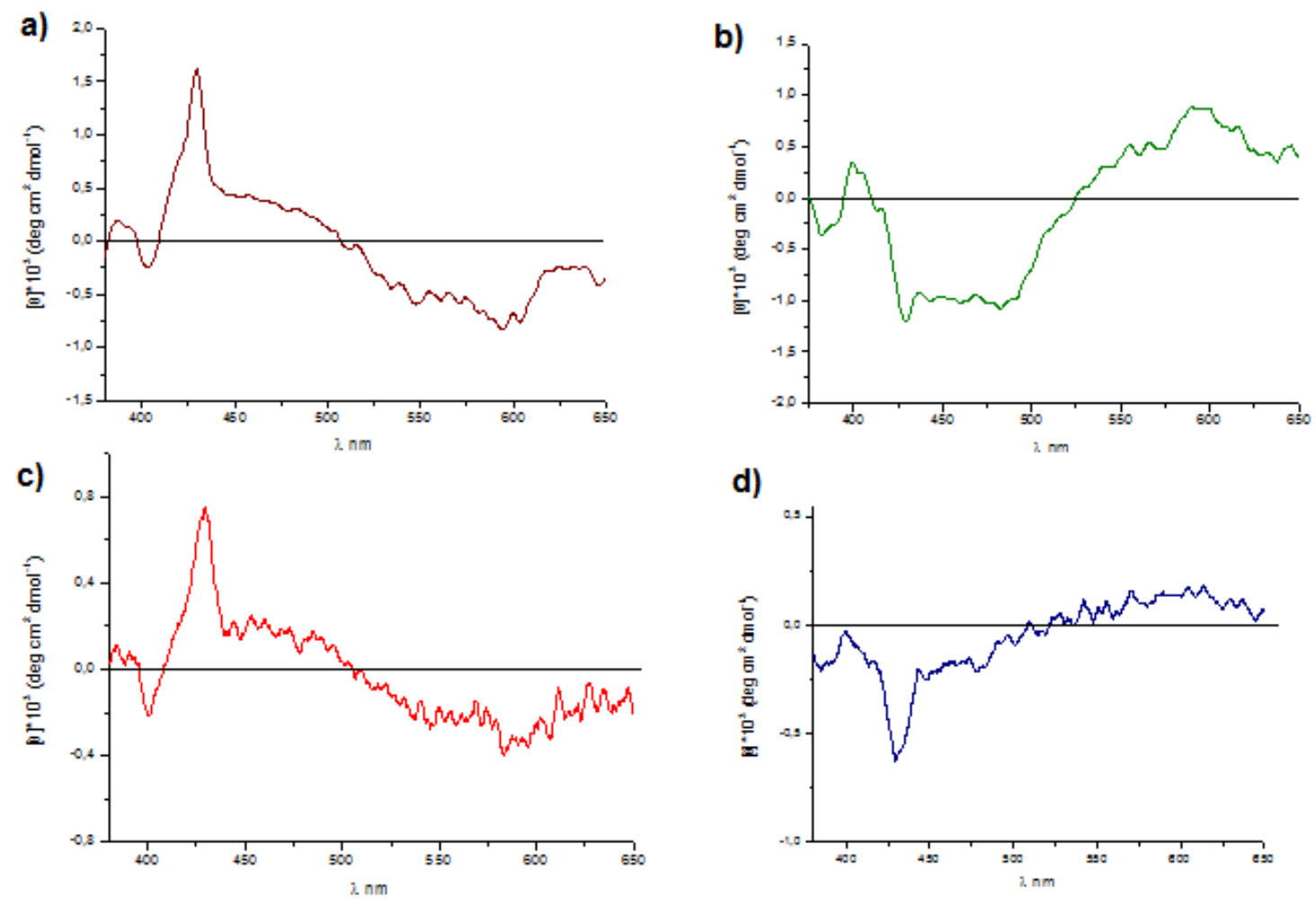

Figure 1. CD spectra of fulleroyrrolidines a) 3-(2S,5R)-cis, b) 4-(2R,5S)-cis, c) 5-(2R,5R)trans, d) 6-(2S,5S)-trans in $\mathrm{CH}_{2} \mathrm{Cl}_{2}$ (conc, $4 \times 10^{-4} \mathrm{M}$ ).

The stereochemical outcome stems from the attack of the $\mathrm{C}_{60}$ onto the $R e, S i$ face of the prochiral C2 an C5 respectively in the case of the stereoisomer $\mathbf{3}$ and onto the opposite face for the stereoisomer 4(See Figure 2). The slight diastereomeric excess is consistent with a weak orientation (chiral induction) of the steroid moiety toward the Re,Si face. 


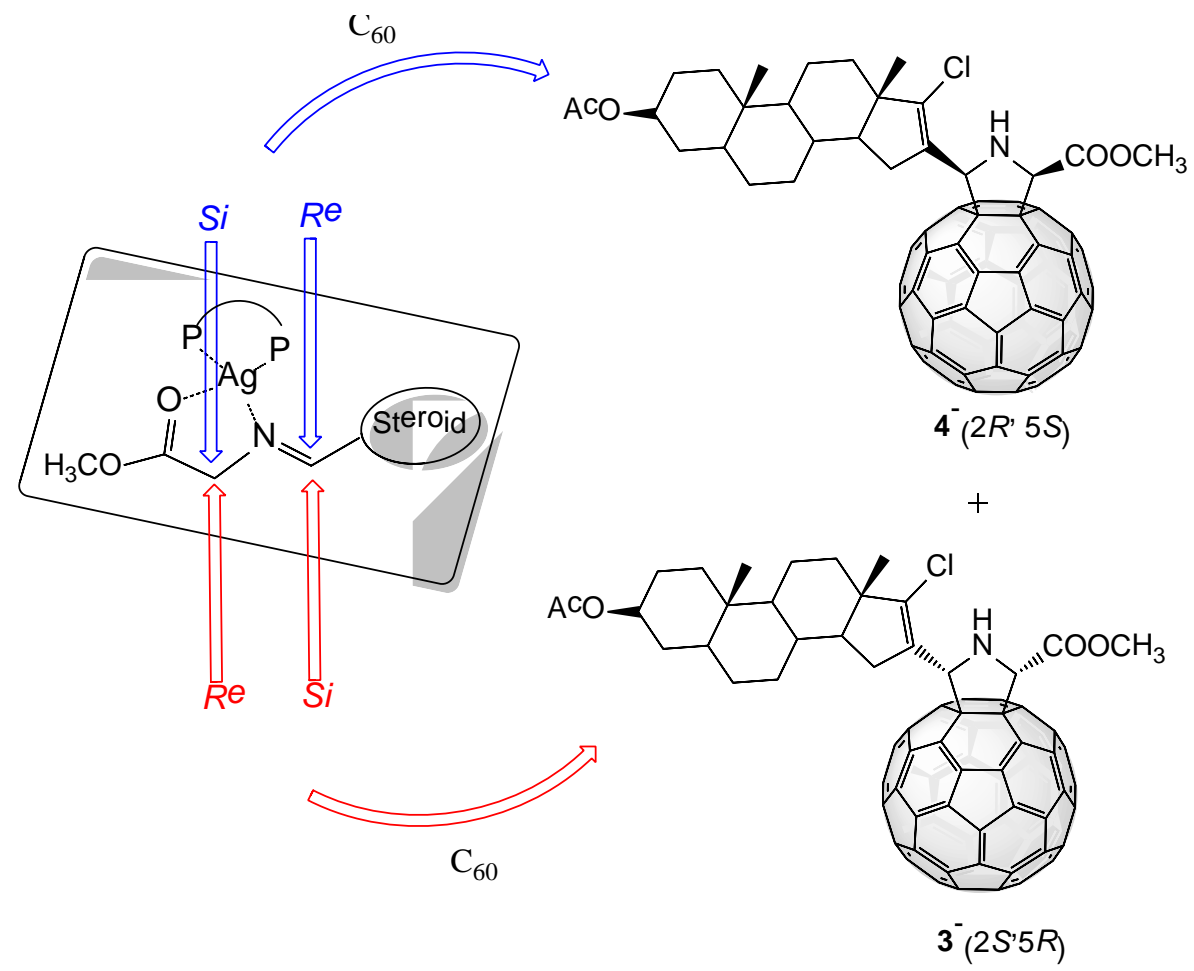

Figure 2. Plausible pathway for the cycloaddition reaction of $\mathrm{C}_{60}$ on the chiral metal complex.

In order to ascertain if the previously reported catalytic systems ${ }^{15,16}$ were able to maintain their stereocontrol in the 1,3-dipolar cycloaddition of azomethine ylides onto $\mathrm{C}_{60}$ even in the presence of a chiral moiety such as the imine $\mathbf{2}$, we performed the reactions using the conditions previously reported. Thus, the catalytic complex $\mathrm{Cu}(\mathrm{II})-$ Fesulphos at $0{ }^{\circ} \mathrm{C}$, directs the 1,3-dipolar cycloaddition of steroid iminoester 2 onto $\mathrm{C}_{60}$ affording cis-(2S,5R)-2-methoxycarbonyl-5-(3' $\beta$-acetoxy-17'-chloro-5' $\alpha$-16'-androstene) pyrrolidino[3,4:1,2] [60]fullerene (3) with an excellent diastereomeric induction. (See Scheme 2 and Table 1, entry 2). 
Table 1. Asymmetric Cu(II) and Ag(I)-catalysed 1,3-dipolar cycloadditions of steroid azomethine ylide to $\mathrm{C}_{60}$ using different chiral ligands.

\begin{tabular}{|c|c|c|c|c|c|c|c|}
\hline Entry $^{\mathrm{a}}$ & Metal/Ligand ${ }^{\mathrm{a}}$ & Temp $^{\circ} \mathrm{C}$ & Conversion $\%^{\mathrm{b}}$ & $\begin{array}{l}3-(2 S, 5 R)- \\
\text { cis } \%\end{array}$ & $\begin{array}{l}\text { 4-(2R,5S)- } \\
\text { cis \% }\end{array}$ & $\begin{array}{l}5-(2 R, 5 R) \\
\text { trans \% }\end{array}$ & $\begin{array}{l}\text { 6-(2S,5S)- } \\
\text { trans } \%\end{array}$ \\
\hline 1 & Ag(AcO)/dppe & $\mathrm{rt}$ & 60 & 32 & 25 & & \\
\hline 2 & $\mathrm{Cu}(\mathrm{AcO})_{2} / \mathrm{FeSulphos}$ & 0 & 80 & 94 & 6 & & \\
\hline 3 & $\mathrm{AgOAc} /(R, R)-\mathrm{BPE}$ & 0 & 88 & 7 & 93 & & \\
\hline 4 & $\begin{array}{l}\mathrm{Cu}(\mathrm{OTf})_{2} / R \text {-DTBM- } \\
\text { Segphos/Et }{ }_{3} \mathrm{~N}\end{array}$ & $\mathrm{rt}$ & 90 & & & 95 & 5 \\
\hline 5 & $\begin{array}{l}\text { Cu(OTf })_{2} / S-D T B M- \\
\text { Segphos/Et } / t_{3} N\end{array}$ & rt & 91 & & & 7 & 93 \\
\hline
\end{tabular}

(a) Conditions (cycloaddition): metal salt (10\% mol), chiral ligand (10\% mol), anhydrous toluene, 2 h; (b) determined by hplc analysis.

Changing the catalytic system to $\operatorname{AgOAc} /(R, R)-\mathrm{BPE}$ at the same temperature (See Scheme 2 and Table 1, entry 3) the cis-diastereoisomer (2R,5S) (cis-2-methoxycarbonyl5-(3' $\beta$-acetoxy-17'-chloro-5' $\alpha$-16'-androstene)pyrrolidino[3,4:1,2][60]fullerene (4) with the opposite configuration is obtained also with excellent diasteroselecivity. Despite the stereoselectivity is slightly lower as result of a mismatched chiral induction between the steroid $(2 R)$ and the catalyst $(2 S)$, the system Ag/BPE is still able to maintain high de values. In both catalysts, the counterion of the metal salt is acetate because it acts as a base and, probably, occupies the vacancy in the metal coordination sphere, thus enabling a better stereodifferentiation. ${ }^{15}$

For completing the diastereodivergent study was important to obtain the transdiastereoisomers. For this, previously reported conditions were used ${ }^{16,17}$ employing the bulky chiral ligand DTBM-Segphos.

In this regard, the complex $\mathrm{Cu}(\mathrm{II})-(R)$-DTBM-Segphos in the presence of triethylamine as a base at room temperature gives a trans-diastereoisomer 5, (See Scheme 2 and Table 1, entry 4) with retention time of $5.9 \mathrm{~min}$ and a positive CE at $430 \mathrm{~nm}$, corresponding with a $(2 R, 5 R)$ configuration (See Figure $1, \mathrm{c})$. The use of $\mathrm{Cu}(\mathrm{II})-(S)$ DTBM-Segphos under the same conditions gives a trans-diastereoisomer 6 (retention time 8.4 min) with (2S,5S), (See Scheme 2 and Table 1, entry 5) configuration, consistent with the negative CE at $430 \mathrm{~nm}$, as it is shown in the CD spectrum (Figure 1, d). 


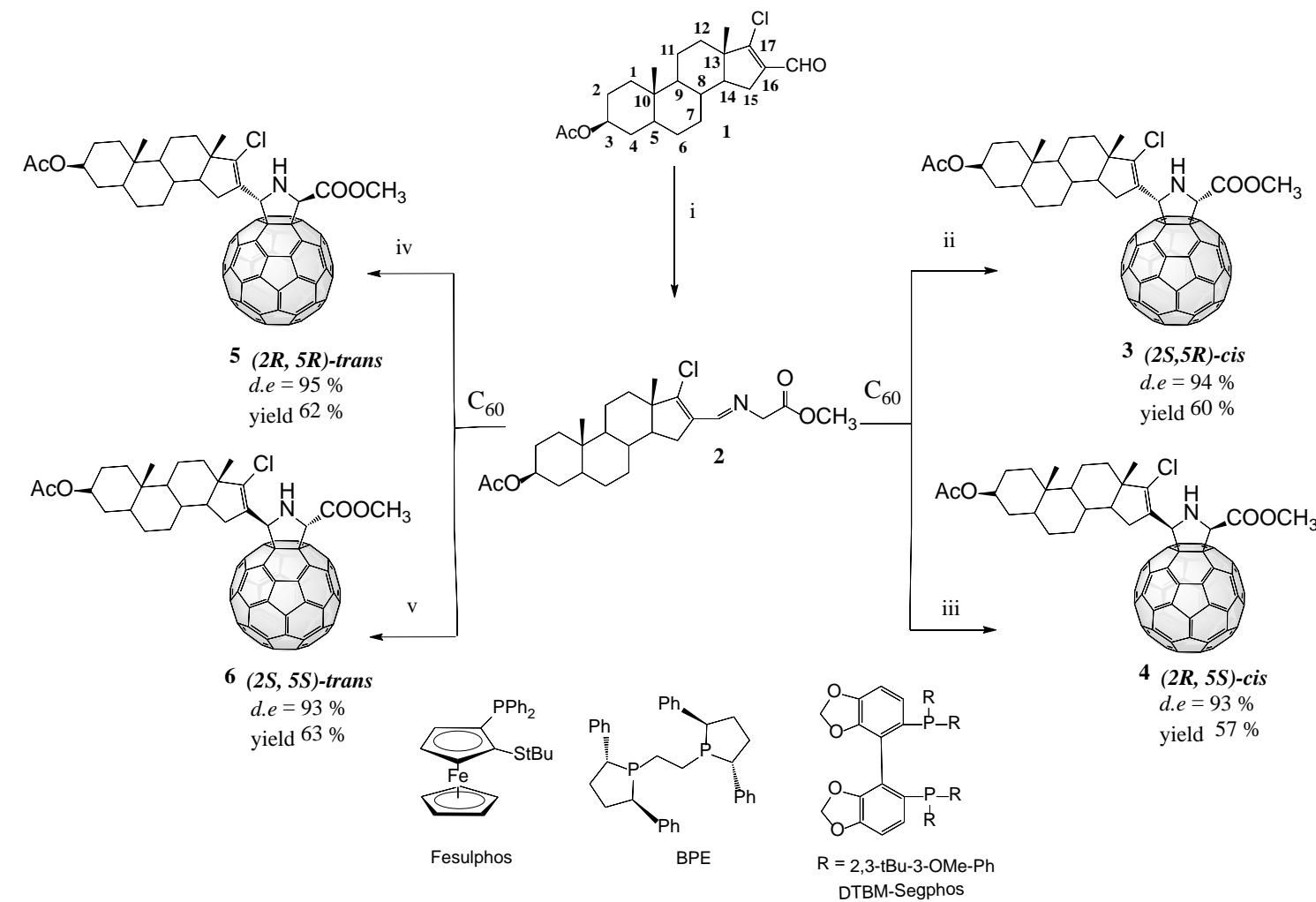

Scheme 2. Stereodivergent synthesis of the four diastereoisomers of 2-methoxycarbonyl5-(3' $\beta$-acetoxy-17'-chloro-5' $\alpha$-16'-androstene)pyrrolidine[3,4:1,2][60]fullerene.

Reagents and conditions: (i) $\mathrm{ClNH}_{3} \mathrm{CH}_{2} \mathrm{COOEt}, \mathrm{Et}_{3} \mathrm{~N}$, DCM anh, rt; (ii) $\mathrm{Cu}(\mathrm{AcO})_{2}$, Fesulphos, $0{ }^{\circ} \mathrm{C}$, 2 h; (iii) $\mathrm{Ag}(\mathrm{OAc})$, BPE, $0{ }^{\circ} \mathrm{C}$, 2 h; (iv) $\mathrm{Cu}(\mathrm{OTf})_{2}, R$-DTBM-Segphos, $\mathrm{Et}_{3} \mathrm{~N}, 2$ h, rt; (v) Cu(OTf) $)_{2}, S$-DTBM-Segphos, $\mathrm{Et}_{3} \mathrm{~N}, 2$ h, rt.

To confirm the trans stereochemistry of diastereoisomers $\mathbf{5}$ and $\mathbf{6}$, ROESY-1D spectra were recorded and no interaction between $\mathrm{H} 2$ and $\mathrm{H} 5$ protons was observed, indicating the trans arrangement between them. (See Suporting Information, Figure S30 for $\mathbf{5}$ and Figure S41 for 6).

The spectroscopical data confirm the structure of both trans-diastereomeric hybrids $\mathbf{5}$ and 6 which are very similar to the cis-diastereisomers 3 and 4. (see the Experimental Section and Supporting Information). ${ }^{1} \mathrm{H}$ NMR shows the signals corresponding to the protons of the pyrrolidine ring at 5.57 ppm (H2) and 5.84 ppm (H5) for 5 and 5.57 ppm (H2) and $5.81 \mathrm{ppm}$ (H5) for 6.

The ${ }^{13} \mathrm{C}$ NMR spectra shows, for both 5 and $\mathbf{6}$, signals at $\sim 76 \mathrm{ppm}$ and $\sim 79 \mathrm{ppm}$, indicating the 6,6-ring junction of $\mathrm{C}_{60}$ to pyrrolidine ring, and those corresponding to the carbons of the fulleropyrrolidine ring which appear at $\sim 74 \mathrm{ppm}(\mathrm{C} 2)$ and $\sim 70 \mathrm{ppm}$ (C5). Also the signals at the interval of 156-136 ppm, denote the presence of the fullerene cage.

MALDI-TOF spectrum for compound 5, registered in the positive mode of detection, shows a peak at $m / z=1170.2405$, corresponding to $[\mathrm{M}+\mathrm{H}]^{+}$ion, while the mass spectrum 
of 6 shows a peak at $m / z=1170.2453$ corresponding to $[\mathrm{M}+\mathrm{H}]^{+}$(See Supporting Information).

The chemical structure of all final compounds (3-6) was confirmed by combined NMR spectroscopic data from ${ }^{1} \mathrm{H},{ }^{13} \mathrm{C}$, COSY, DEPT, HMQC, and HMBC experiments. (See Supporting Information).

Also the specific optical rotation measurements for the hybrids were carried out. Thus, the experimentally determined values for $[\alpha]_{\mathrm{D}}{ }^{20}$ were: $+125^{\circ}$ for 3 -cis, $+40^{\circ}$ for 4 -cis, $+105^{\circ}$ for $\mathbf{5}$-trans and $+35^{\circ}$ for $\mathbf{6}$-trans.

The 1,3-dipolar cycloaddition between the steroidal imine 2 and [60]fullerene is coherent with the previous results obtained by Martin et al. for the synthesis of stereodivergent chiral fulleropyrrolidines. ${ }^{15}$

\section{CONCLUSIONS}

In summary, we have carried out for the first time a controlled diastereoselective synthesis of chiral steroid-fulleropyrrolidines by reaction of copper or silver $N$-metalated azomethine ylide and chiral ligands. Depending on the chiral metal/ligand employed, it is possible to obtain the pairs of cis and trans diastereomers with good diastereomeric excesses and good yields. The new steroid-fullerene hybrids have been characterized by spectroscopic and dichroic study which reveal the formation of the four different stereoisomers. Importantly, these results show that the azomethine ylides stabilized by an allylic group generated from the steroidal imine $\mathbf{2}$, behaves in a similar favorable way to that observed for the benzyl related compounds in previous studies (see above).

In contrast to previous papers involving steroid-fullerene hybrids where only poor stereoselectivities were achieved, the stereodivergent protocol now presented shows the efficiency for the preparation of diastereoselective derivatives in a controlled manner, thus paving the way to a great variety of optically active fullerene derivatives.

\section{EXPERIMENTAL}

General Experimental Methods. All reactions were performed using an atmosphere of argon and oven-dried glassware. Solvents were treated prior to use according to the standard methods. The commercially available reagents were used without further purification. Reactions were monitored by thin-layer chromatography carried out on 0.25 mm silicagel plates (230-400 mesh). Flash column chromatography was performed using 
silica gel (60 $\AA, 32-63 \mu \mathrm{m})$. FTIR spectra were recorded in $\mathrm{CHCl}_{3} .{ }^{1} \mathrm{H}-\mathrm{NMR}$ spectra were recorded at $700 \mathrm{MHz}$ and ${ }^{13} \mathrm{C}-\mathrm{NMR}$ at $175 \mathrm{MHz}$; the one-bond heteronuclear correlation (HMQC) and the long-range ${ }^{1} \mathrm{H}-{ }^{13} \mathrm{C}$ correlation (HMBC) spectra were obtained by use of the inv4gs and the inv4gslplrnd programs. All MS-ESI and HRMS-MALDI (dithranol as matrix) experiments were carried out in negative and positive modes of detection. $\mathrm{UV} /$ vis spectra were recorded in $\mathrm{CHCl}_{3}$. Microanalysis was performed with a $\mathrm{CHN}$ instrument. Optical rotations were measured using a polarimeter with a thermally jacketed $10 \mathrm{~cm}$ cell at $20^{\circ} \mathrm{C}$ (concentration given as $\mathrm{g} / 100 \mathrm{ml}$ ). The CD spectra were recorded in dichloromethane. A high-performance liquid chromatography (HPLC) system (column

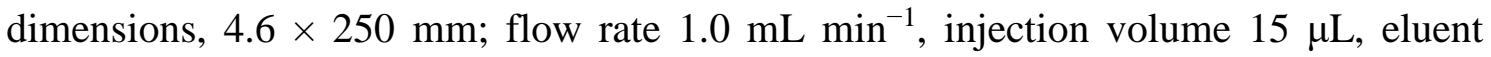
toluene:acetonitrile 9:1) was used to determine the purity of the compounds synthesized and de values All these values were monitored in a $320 \mathrm{~nm}$ spectrophotometer detector.

\section{N-methyl [(3ß-acetoxy-17-chloro-16-androstene-16-yl) methylene] glycinate) (2). A} mixture of glycine methyl ester hydrochloride $75 \mathrm{mg}(0.6 \mathrm{mmol})$ and triethyl amine 0.26 $\mathrm{mL}$ (1.8 mmol) with molecular sieves $(4 \AA)$ in $40 \mathrm{~mL}$ of anhydrous dichloromethane (DCM) was stirred for one hour. Then, 3 $\beta$-acetoxy-17-chloro-16-formyl-5 $\alpha$-16androstene $160 \mathrm{mg}$ (0.42 mmol) was added and the reaction was stirred overnight at room temperature. The reaction mixture was filtered to separate the molecular sieves and the filtrate was washed twice with water and subsequently over anhydrous $\mathrm{MgSO}_{4}$. The organic extract was concentrated, obtaining a yellow oil. Yield $77 \%$ (145 mg). ${ }^{1} \mathrm{H}-\mathrm{NMR}$ (700 MHz, $\mathrm{CDCl}_{3}, \delta$ ppm): $8.22(\mathrm{~s}, 1 \mathrm{H}, \mathrm{CH}=\mathrm{N}), 4.67(\mathrm{~m}, 1 \mathrm{H}, \mathrm{H} 3), 4.31\left(\mathrm{~s}, 2 \mathrm{H}, \mathrm{NCH}_{2} \mathrm{CO}\right)$, 3.76 (s, 3H, $\mathrm{CH}_{3} \mathrm{O}$ ), 2.63 (dd, $J=14.7 \mathrm{~Hz}, J=6.0 \mathrm{~Hz}, 1 \mathrm{H}, \mathrm{H} 15$ ), 2.04 (m, 1H, H15), 2.01 (s, 3H, $\left.\mathrm{CH}_{3}-\mathrm{CO}\right), 1.84$ (m, 1H, H2), 1.78 (m, 1H, H7), 1.73 (m, 1H, H1), 1.67 (m, 2H, H11), 1.63 (m, 1H, H4), 1.59 (m, 1H, H14), 1.57 (m, 1H, H8), 1.51 (m, 1H, H2), 1.46 (m, 1H, H12), 1.42 (m, 1H, H12), 1.38 (m, 1H, H4), 1.33 (m, 2H, H11), 1.30 (m, 2H, H6), 1.20 (m, 1H, H5), 1.03 (m, 1H, H1), 0.97 (m, 1H, H7), 0.84 (m, 1H, H9).0.82 (s, 3H, $\left.\mathrm{CH}_{3}-19\right), 0.74$ (s, 3H, $\left.\mathrm{CH}_{3}-18\right) .{ }^{13} \mathrm{C}-\mathrm{NMR}\left(175 \mathrm{MHz}, \mathrm{CDCl}_{3}, \delta \mathrm{ppm}\right): 170.7(\mathrm{C}=\mathrm{O}), 170.6$ $(\mathrm{C}=\mathrm{O}), 160.7(\mathrm{CH}=\mathrm{N}), 152.7$ (C17), 134.9 (C16), 73.5 (C3), $62.3\left(\mathrm{NCH}_{2} \mathrm{CO}\right), 54.6$ (C14), 53.9 (C9), 52.2 ( $\left.\mathrm{CH}_{3} \mathrm{O}\right), 49.9$ (C13), 44.8 (C5), 36.5 (C1), 35.7 (C10), 34.0 (C8), 33.9 (C12), 33.4 (C4), 31.1 (C7), 28.3 (C15), 28.2 (C6), 27.4 (C2), 21.5 ( $\left.\mathrm{CH}_{3}-\mathrm{CO}\right), 20.7$ (C11), 15.2 (C18), 12.2 (C19). IR $\left(\mathrm{CHCl}_{3}\right): v=$ 3242, 2927, 2858, $1732(\mathrm{C}=\mathrm{O}), 1674,1244$, 1026, $756 \mathrm{~cm}^{-1}$. $\mathrm{C}_{25} \mathrm{H}_{36} \mathrm{ClNO}_{4}$ (449.23): calcd. C 66.72, H 8.06; found C 66.75, H 8.10. MS (MALDI-TOF) m/z: [M + Na $]^{+} 472.3$. 
cis-(2S,5R)-2-Methoxycarbonyl-5-(3' $\beta$-acetoxy-17'-chloro-5' $\alpha$-16'-androstene)

pyrrolidino[3,4:1,2][60]fullerene (3). A mixture of $\mathrm{Cu}(\mathrm{OAc})_{2}(1 \mathrm{mg})$ and Fesulfos (2.3 $\mathrm{mg})$ in anhydrous toluene $(10 \mathrm{~mL})$ was stirred for one hour at room temperature. Then, $20 \mathrm{mg}$ of steroid $\alpha$-iminoester 1 was added and the yellow mixture was cooled at $0^{\circ} \mathrm{C}$. Finally, $30 \mathrm{mg}$ (0.042 mmol) of $\mathrm{C}_{60}$ was also added. The reaction mixture was stirred for two hours, and afterwards, it was quenched with an aqueous saturated ammonium chloride solution ( $3 \mathrm{~mL}$ ). The mixture was extracted with toluene ( $3 \times 1 \mathrm{~mL})$, and the combinated extracts were washed with brine $(3 \mathrm{~mL})$. The organic layer was dried over MgSO4 and concentrated in vacuo. The solid crude was purified by column chromatography on silica gel, using $\mathrm{CS}_{2}$ to elute unreacted $\mathrm{C}_{60}$ and dichloromethane to elute the corresponding pyrrolidine [3,4:1.2][60]fullerene 3. Brown solid, melting point over $350^{\circ}$ C. Chemical yield: $60 \%$ (29 mg). HPLC: toluene, flow rate $1 \mathrm{~mL} / \mathrm{min}, t_{\mathrm{R}}=$ 6.96 min. $[\alpha]_{\mathrm{D}}{ }^{20}=+125^{\circ}$ (c $2 \times 10^{-4} \mathrm{CH}_{2} \mathrm{Cl}_{2}$ ). ${ }^{1} \mathrm{H}-\mathrm{RMN}$ (700 MHz, $\mathrm{CDCl}_{3}, \delta$ ppm): 5.81 (s, 1H, H5), 5.57 (s, 1H, H2), 4.65 (m, 1H, H3'), 3.90 (s, 3H, $\mathrm{CH}_{3} \mathrm{O}$ ), 2.60 (dd, $J=14.5$ Hz, $J=6.3 \mathrm{~Hz}, 1 \mathrm{H}, \mathrm{H} 15$ '), 2.44 (dd, $J=14.4 \mathrm{~Hz}, J=11.6 \mathrm{~Hz}, 1 \mathrm{H}, \mathrm{H} 15$ '), 2.03 (s, 3H, CH $3 \mathrm{CO}$ ), 1.80 (m, 1H, H2'), 1.77 (m, 1H, H12'), 1.74 (m, 1H, H7'), 1.68 (m, 1H, H1'), 1.61 (m, 1H, H8'), 1.60 (m, 1H, H11'), 1.58 (m, 1H, H4'), 1.47 (m, 1H, H2'), 1.37 (m, 1H, H11'), 1.35 (m, 1H, H4'), 1.33 (m, 1H, H14'), 1.30 (m, 2H, H6'), 1.21 (m, 1H, H12'), 1.17 (m, 1H, H5'), 1.01 (s, 3H, CH $3-18$ '), 0.99 (m, 1H, H1'), 0.86 (s, 3H, $\mathrm{CH}_{3}-19$ '), 0.82 (m, 1H, H7’), 0.67 (m, $\left.J=4.6 \mathrm{~Hz}, 1 \mathrm{H}, \mathrm{H} 9{ }^{\prime}\right) .{ }^{13} \mathrm{C}-\mathrm{RMN}$ (175 MHz, $\mathrm{CDCl}_{3}, \delta \mathrm{ppm}$ ): 170.7 $(\mathrm{C}=\mathrm{O}) ; 169.9$ (C=O-C2), 153.3, 152.5, 151.7, 150.7, 147.2, 147.0, 146.5, 146.4, 146.33, 146.29, 146.2, 146.1, 145.9, 145.5, 145.4, 145.38, 145.35, 145.3, 145.2, 145.16, 145.1, 144.9 (C17'), 144.5, 144.3, 144.2, 144.1, 143.2, 143.1, 143.0, 142.8, 142.7, 142.7, 142.5, 142.4, 142.3, 142., 142.1, 142.0, 141.9, 141.8, 141.6, 140.0, 139.8, 139.7, 139.6, 136.6, 136.1, 135.3, 134.8, 132.0 (C16'), 79.8 (Csp ${ }^{3} \mathrm{C}_{60}$ ), 76.9 (Csp ${ }^{3} \mathrm{C}_{60}$ ), 74.0 (C2), 73.5 (C3’), 70.5 (C5), 55.2 (C14'), 54.5 (C9’), 53.5 ( $\left.\mathrm{CH}_{3} \mathrm{O}\right), 48.9$ (C13’), 44.6 (C5’), 36.3 (C1'), 35.7 (C10’), 34.2 (C12'), 33.9 (C4'), 33.7 (C8'), 32.2 (C15’), 31.4 (C7’), 28.2 (C6'), 27.4 (C2'), 21.5 ( $\left.\mathrm{CH}_{3} \mathrm{CO}\right), 20.8$ (C11'), 15.1 (C18'), 12.2 (C19'). IR ( $\left.\mathrm{CHCl}_{3}\right): v=2924,2854$, 1737 (C=O), 1249, 1025, $755 \mathrm{~cm}^{-1}$. HRMS (MALDI-TOF) m/z: [M-] Calcd for $\mathrm{C}_{85} \mathrm{H}_{36} \mathrm{ClNO}_{4}$ 1169.2338; Found 1169.2330.

\section{cis-(2R,5S)-2-Methoxycarbonyl-5-(3' $\beta$-acetoxy-17'-chloro-5' $\alpha-16$ '-androstene)}

pyrrolidino[3,4:1,2][60]fullerene. (4). A mixture of AgOAc (1 mg) and BPE (2.3 mg) in toluene anhydrous $(10 \mathrm{~mL})$ in toluene anhydrous $(10 \mathrm{~mL})$ was stirred for one hour at room 
temperature. Then, $20 \mathrm{mg}$ of steroid $\alpha$-iminoester $\mathbf{1}$ was added and the yellow mixture was cooled at $0^{\circ} \mathrm{C}$. Finally, $30 \mathrm{mg}(0.042 \mathrm{mmol})$ of $\mathrm{C}_{60}$ was also added. The reaction mixture was stirred for two hours, and afterwards, it was quenched with an aqueous saturated ammonium chloride solution ( $3 \mathrm{~mL}$ ). The mixture was extracted with toluene ( $3 \times 1 \mathrm{~mL})$, and the combinated extracts were washed with brine $(3 \mathrm{~mL})$. The organic layer was dried over $\mathrm{MgSO}_{4}$ and concentrated in vacuo. The solid crude was purified by column chromatography on silica gel, using $\mathrm{CS}_{2}$ to elute unreacted $\mathrm{C}_{60}$ and dichloromethane:ethyl acetate (100:1) to elute the corresponding pyrrolidine [3,4:1.2][60]fullerene 4. Brown solid, melting point over $350^{\circ} \mathrm{C}$. Chemical yield: 57 \% (27 mg). HPLC: toluene, flow rate $1 \mathrm{~mL} / \mathrm{min}, t_{\mathrm{R}}=10.71 \mathrm{~min}$. $[\alpha]_{\mathrm{D}}{ }^{20}=+40^{\circ}$ (c $\left.2 \times 10^{-4} \mathrm{CH}_{2} \mathrm{Cl}_{2}\right) .{ }^{1} \mathrm{H}-\mathrm{RMN}(700 \mathrm{MHz}$, $\left.\mathrm{CDCl}_{3}, \delta \mathrm{ppm}\right): 5.86$ (s, 1H, H5), 5.58 (s, 1H, H2), 4.71 (m, 1H, H3'), 3.90 (s, 3H, $\mathrm{CH}_{3} \mathrm{O}$ ), 2.72 (dd, $J=14.5 \mathrm{~Hz}, J=6.4 \mathrm{~Hz}, 1 \mathrm{H}, \mathrm{H} 15$ '), 2.14 (dd, $J=13.8 \mathrm{~Hz}, J=11.9 \mathrm{~Hz}, 1 \mathrm{H}$, H15'), 2.03 (s, 3H, CH3CO), 1.83 (m, 1H, H2'), 1.80 (m, 1H, H7'), 1.77 (m, 1H, H12'), 1.73 (m, 1H, H14'), 1.70 (m, 1H, H1'), 1.66 (m, 1H, H11'), 1.62 (m, 1H, H8'), 1.57 (m, 1H, H4'), 1.49 (m, 1H, H2'), 1.40 (m, 1H, H12'), 1.38 (m, 1H, H4'), 1.35 (m, 1H, H11'), 1.33 (m, 1H, H6’), 1.29 (m, 1H, H6’), 1.24 (m, 1H, H5'), 1.09 (m, 1H, H7'), 1.03 (m, 1H, H1'), 0.84 (m, 1H, H9'), 0.83 (s, 3H, CH3-19'), 0.75 (s, 3H, CH $\mathrm{CH}_{3}-18$ '). ${ }^{13} \mathrm{C}-\mathrm{RMN}$ (175 $\left.\mathrm{MHz}, \mathrm{CDCl}_{3}, \delta \mathrm{ppm}\right): 170.9$ (CO-20’), 170.1 (CO-C2), 153.6, 152.9, 152.1, 150.9, 147.3, 147.2, 146.7, 146.5, 146.44, 146.42, 146.38, 146.2, 146.1, 146.0, 145.7, 145.60, 145.57 (C17'), 145.5, 145.47, 145.39, 145.35, 145.33, 145.30, 144.5, 144.48, 144.45, 144.3, 143.27, 143.25, 143.17, 142.92, 142.89, 142.84, 142.81, 142.76, 142.6, 142.4, 142.3, 142.2, 142.14, 142.11, 142.09, 142.06, 141.98, 141.2, 139.90, 139.83, 139.75, 136.8, 136.25, 136.17, 135.0, 131.7 (C16’), 79.4 (Csp ${ }^{3}$ C60), 76.9 (Csp $\left.{ }^{3} \mathrm{C}_{60}\right), 73.8$ (C2), 73.7 (C3’), 70.7 (C5), 55.12 (C14’), 54.7 (C9’), $53.0\left(\mathrm{OCH}_{3}\right), 49.1$ (C13’), 44.9 (C5’), 36.6 (C1'), 35.9 (C10'), 34.10 (C8'), 34.08 (C4'), 33.6 (C12'), 32.1 (C15'), 31.4 (C7'), 28.4 (C6’), 27.5 (C2’), 21.6 (C21'), 20.8 (C11'), 16.2 (C18'), 12.3 (C19’). IR ( $\left.\mathrm{CHCl}_{3}\right): v=$ 2928, 2853, 1737 (C=O), 1249, 1025, $754 \mathrm{~cm}^{-1}$. HRMS (MALDI-TOF) m/z: [M + Na] ${ }^{+}$ Calcd for $\mathrm{C}_{85} \mathrm{H}_{36} \mathrm{ClNO}_{4} \mathrm{Na}$ 1192.2225; Found 1192.2223.

\section{trans-(2R,5R)-2-Methoxycarbonyl-5-(3' $\beta$-acetoxy-17'-chloro-5' $\alpha$-16'-androstene)}

pyrrolidino[3,4:1,2][60]fullerene. (5). A mixture of cooper(II)triflate (1.9 mg) and $R$ DTBM-Segphos (6 mg) in toluene anhydrous $(10 \mathrm{~mL})$ was stirred for one hour at room temperature, getting a solution with a slight blue colour. Then, $23.5 \mathrm{mg}$ of steroid $\alpha$ iminoester 1 was added obtaining a yellow mixture. Finally, $\mathrm{C}_{60}(33.6 \mathrm{mg})$ and $0.2 \mathrm{~mL}$ of 
triethylamine were added. The reaction mixture was stirred for two hours, and afterwards, it was quenched with an aqueous saturated ammonium chloride solution (5 mL). The mixture was extracted with toluene ( $3 \times 10 \mathrm{~mL})$, and the combinated extracts were washed with brine $(10 \mathrm{~mL})$. The organic layer was dried over $\mathrm{MgSO}_{4}$ and concentrated in vacuo. The crude product was purified by column chromatography on silica gel, using $\mathrm{CS}_{2}$ to elute unreacted $\mathrm{C}_{60}$ and dichloromethane to elute the corresponding pyrrolidine [3,4:1.2][60]fullerene 5. Chemical yield: 62 \% (29 mg). Brown Solid. HPLC: toluene, flow rate $1 \mathrm{~mL} / \mathrm{min}, t_{\mathrm{R}}=5.91 \mathrm{~min}$. $[\alpha]_{\mathrm{D}}{ }^{20}=+105^{\circ}$ (c $2 \times 10^{-4} \mathrm{CH}_{2} \mathrm{Cl}_{2}$ ). ${ }^{1} \mathrm{H}-\mathrm{NMR}(700$ MHz, $\mathrm{CDCl}_{3}, \delta$ ppm): 5.84 (s, 1H, H5), 5.57 (s, 1H, H2), 4.65 (m, 1H, H3’), 3.66 (s, 3H, $\mathrm{CH}_{3} \mathrm{O}$ ), 2.60 (m, 1H, H15'), 2.44 (m, 1H, H15'), 2.01 (s, 3H, $\mathrm{CH}_{3} \mathrm{CO}$ ), 1.82 (m, 1H, H2'), 1.78 (m, 1H, H12'), 1.76 (m, 1H, H7'), 1.70 (m, 1H, H1'), 1.63 (m, 1H, H11'), 1.61 (m, 1H, H8'), 1.58 (m, 1H, H4'), 1.50 (m, 1H, H2'), 1.39 (m, 1H, H11'), 1.38 (m, 1H, H4'), 1.37 (m, 1H, H14'), 1.33 (m, 1H, H6’), 1.29 (m, 1H, H6’), 1.23 (m, 1H, H12'), 1.18 (m, 1H, H5'), 1.02 (m, 1H, H1'), 0.89 (s, 3H, CH3-18'), 0.85 (s, 3H, $\mathrm{CH}_{3}-19$ '), 0.82 (m, 1H, H7’), 0.68 (m, 1H, H9’). ${ }^{13} \mathrm{C}-\mathrm{NMR}$ (175 MHz, $\mathrm{CDCl}_{3}, \delta$ ppm): 170.61 (CO-20’), 169.70 (CO-C2), 147.14, 147.00, 146.34, 146.23, 145.99, 145.94, 145.57, 145.44, 145.40, 145.33, 145.26, 145.14, 144.51, 143.31, 144.25, 143.15, 143.09, 142.74, 142.73, 142.68, 142.65, 142.54, 142.41, 142.30, 142.28, 142.14, 142.05, 142.04, 142.00, 141.91, 140.03, 139.68, 137.86 (C17’), 129.02 (C16’), 79.68 (Csp ${ }^{3}$ C60), 76.38 (Csp ${ }^{3}$ C60), 74.09 (C2), 73.47 (C3’), 70.74 (C5), 70.57 (OCH 3 ), 55.17 (C14’), 54.48 (C9’), 48.86 (C13’), 44.64 (C5’), 36.32 (C1’), 35.71 (C10’), 34.25 (C4’), 33.90 (C12’), 33.71 (C8’), 31.34(C15’), 29.69 (C7’), 28.21 (C6'), 27.36 (C2’), 21.43 (C21'), 20.66 (C11'), 14.35 (C18’), 12.15 (C19'). IR $\left(\mathrm{CHCl}_{3}\right): v=2923,2854,1738,1678,1522,743 \mathrm{~cm}^{-1}$. HRMS (MALDI-TOF) $\mathrm{m} / \mathrm{z}:[\mathrm{M}+\mathrm{H}]^{+}$Calcd for $\mathrm{C}_{85} \mathrm{H}_{37} \mathrm{ClNO}_{4}$ 1170.2411; Found 1170.2405.

\section{trans-(2S,5S)-2-methoxycarbonyl-5-(3' $\beta$-acetoxy-17'-chloro-5' $\alpha-16$ '-androstene}

pyrrolidino[3,4:1,2][60]fullerene (6). A mixture of cooper(II)triflate (2 mg) and $S$ DTBM-Segphos (6 mg) in toluene anhydrous $(10 \mathrm{~mL})$ was stirred for one hour at room temperature, getting a solution with a slight blue colour. Then, $23.5 \mathrm{mg}$ of steroid $\alpha$ iminoester 1 was added obtaining a yellow mixture. Finally, $\mathrm{C}_{60}(33 \mathrm{mg})$ and $0.2 \mathrm{~mL}$ of triethylamine were added. The reaction mixture was stirred for two hours, and afterwards, it was quenched with an aqueous saturated ammonium chloride solution (5 mL). The mixture was extracted with toluene $(3 \times 10 \mathrm{~mL})$, and the combinated extracts were washed with brine $(10 \mathrm{~mL})$. The organic layer was dried over $\mathrm{MgSO}_{4}$ and concentrated in vacuo. 
The crude product was purified by column chromatography on silica gel, using $\mathrm{CS}_{2}$ to elute unreacted $C_{60}$ and dichloromethane:ethyl acetate (99:1) to elute the corresponding pyrrolidine [3,4:1.2][60]fullerene 6. Chemical yield: $63 \%$ (30 mg). Brown Solid. HPLC: solvent toluene, flow rate $1 \mathrm{~mL} / \mathrm{min}, t_{\mathrm{R}}=8.42 \mathrm{~min}$. $[\alpha]_{\mathrm{D}}{ }^{20}=+35^{\circ}\left(\right.$ c $\left.2 \times 10^{-4} \mathrm{CH}_{2} \mathrm{Cl}_{2}\right) .{ }^{1} \mathrm{H}$ NMR (700 MHz, $\mathrm{CDCl}_{3}, \delta$ ppm): 5.81 (s, 1H, H5), 5.57 (s, 1H, H2), 4.69 (m, 1H, H3’), 3.90 (s, 3H, $\mathrm{CH}_{3} \mathrm{O}$ ), 2.60 (m, 1H, H15'), 2.44 (m, 1H, H15'), 2.01 (s, 3H, $\mathrm{CH}_{3} \mathrm{CO}$ ), 1.82 (m, 1H, H2'), 1.77 (m, 1H, H12'), 1.76 (m, 1H, H7'), 1.70 (m, 1H, H1'), 1.61 (m, 1H, H11'), 1.60 (m, 1H, H8'), 1.58 (m, 1H, H4'), 1.49 (m, 1H, H2'), 1.39 (m, 1H, H4'), 1.38 (m, 1H, H14'), 1.37 (m, 1H, H11'), 1.34 (m, 1H, H6'), 1.31 (m, 1H, H6'), 1.22 (m, 1H, H12'), 1.18 (m, 1H, H5'), 1.02 (m, 1H, H1'), 0.89 (s, 3H, CH CH $_{3}$ '), 0.86 (s, 3H, CH${ }^{-}$ 19'), 0.83 (m, 1H, H7'), 0.67 (m, 1H, H9'). ${ }^{13} \mathrm{C}-\mathrm{NMR}$ (175 MHz, $\mathrm{CDCl}_{3}, \delta \mathrm{ppm}$ ): 170.7 (CO-20'), 169.9 (CO-C2), 147.1, 147.0, 146.3, 146.0, 145.6, 145.4, 145.3, 145.2, 144.5, 144.3, 144.2, 143.2, 143.1, 142.74, 142.67, 142.65, 142.5, 142.4, 142.3, 142.1, 142.05 , 142.00, 141.9, 141.8, 140.04, 140.03, 139.7, 138.0 (C17'), 128.9 (C16'), 79.8 (Csp³ C60), 77.2 (- $\left.\mathrm{Csp}^{3} \mathrm{C}_{60}\right), 74.1$ (C2), 73.5 (C3’), $70.6\left(\mathrm{OCH}_{3}\right), 70.5$ (C5), 55.2 (C14'), 54.5 (C9'), 48.9 (C13’), 44.6 (C5’), 36.4 (C1’), 35.7 (C10’), 34.3 (C4’), 33.9 (C12'), 33.7 (C8’), 31.4 (C15’), 29.4 (C7’), 28.2 (C6’), 27.4 (C2'), 21.5 (C21'), 20.7 (C11'), 14.2 (C18'), 12.2 (C19'). IR $\left(\mathrm{CHCl}_{3}\right): v=2924,2853,1738,1250,1025,723 \mathrm{~cm}^{-1}$. HRMS (MALDI-TOF) m/z: $[\mathrm{M}+\mathrm{H}]^{+}$Calcd for $\mathrm{C}_{85} \mathrm{H}_{37} \mathrm{ClNO}_{4}$ 1170.2411; Found 1170.2453.

\section{ACKNOWLEDGMENTS}

Financial support by the European Research Council (ERC-320441-Chirallcarbon), the Ministerio de Economía y Competitividad (MINECO) of Spain (project CTQ201452045-R) and the Comunidad Autónoma de Madrid (PHOTOCARBON project S2013/MIT-2841) is acknowledged.

\section{SUPPORTING INFORMATION}

The Supporting Information is available free of charge on the ACS Publications website:

${ }^{1} \mathrm{H}-\mathrm{NMR}$ and ${ }^{13} \mathrm{C}$ NMR (1D and 2D), MS, IR and UV spectra and HPLC chromatograms.

\section{REFERENCES}


(1) (a) Huang, Y. Y.; Sharma, S.K.; Yin, R.; Agrawal, T.; Chiang, L.Y.; Hamblin, M.R. J. Biomed. Nanotechnol. 2014, 10, 1918-1936. (b) Partha, R.; Conyers, J. L Int. J. Nanomed. 2009, 4, 261-271.

(2) Mehta, G.; Singh V. Chem. Soc. Rev.2002, 31, 324-334.

(3) Salunke, D. B.; Hazra, B. G.; Pore, V. S. Curr. Med. Chem. 2006, 13, 813-847.

(4) Burendic, E.; Penov-Gasi, K.; Medic-Mejacevic, L. Hemijski Pregled, 2002, 43, 8284.

(5) Fong, R. II; Schuster, D. I.; Wilson, S. R. Org. Lett. 1999, 1, 729-732.

(6) Ishi,-I, T.; Shinkai, S., Tetrahedron 1999, 55, 12515-12530.

(7) Li, L.; Hu, Y.; Wu, Y.; Wu, Y.; Yue, J.; Yang, F., J. Chem. Soc., Perkin Trans. 1, 2001, 617-621.

(8) Bjelakovic, M. S.; Godjevac, D. M.; Milic, D. R. Carbon, 2007, 45, 2260-2265.

(9) MacFarland, D.; Zhang, J.; Zhou, Z.; Lenk, R. P.; Wilson, S. R. U.S. Pat. Appl. Publ. 2008, US 20080214514 A1 20080904.

(10) Bjelakovic, M.; Kop, T.; Baosic, R.; Zlatovic, M.; Zekic, A.; Maslak, V.; Milic, D Monatsh. Chem. 2014, 145, 1715-1725.

(11) Bjelakovic, M. S.; Kop, T. J.; Vlajic, M.; Djordjevic, J.; Milic, D. R. Tetrahedron 2014, 70, 8564-8570.

(12) Coro, J.; Rodriguez, H.; Rivera, D. G.; Suarez, M.; Molero, D.; Herranz, M. A.; Martinez-Alvarez, R.; Filippone, S.; Martin, N. Eur. J. Org. Chem. 2009, 4810-4817.

(13) Ruiz, A.; Coro, J.; Almagro, L.; Ruiz, J. A.; Molero, D.; Maroto, E. E.; Filippone, S.; Herranz, M. A.; Martinez-Alvarez, R.; Sancho-Garcia, J. C.; Di Meo F.; Suarez, M.; Martín, N. J. Org. Chem. 2013, 78, 2819-2826.

(14) Ruiz, A.; Morera-Boado, C.; Almagro, L.; Coro, J.; Maroto, E. E.; Herranz, M. A.; Filippone, S.; Molero, D.; Martinez-Alvarez, R.; Garcia de la Vega, J. M.; Suárez, M.; Martín, N. J. Org. Chem. 2014, 79, 3473-3486.

(15) Filippone, S.; Maroto, E. E.; Martín-Domenech, A.; Suárez, M.; Martín, N. Nat. Chem. 2009, 1, 578-582.

(16) Maroto, E. E.; Filippone, S.; Martín-Domenech, A.; Suárez, M.; Martín, N. J. Am. Chem. Soc. 2012, 134, 12936-12938.

(17) Maroto, E. E.; Filippone, S.; Suárez, M.; Martínez-Álvarez, R.; de Cózar, A.; Cossío, F. P.; Martín, N. J. Am. Chem. Soc. 2014, 136, 705-712. 
(18) Maroto, E. E.; Izquierdo, M.; Reboredo, S.; Marco-Martínez, J.; Filippone, S.; Martín, N. Acc. Chem. Res. 2014, 47, 2660-2670.

(19) Wilson, S. R.; Lu, Q.; Cao, J.; Wu, Y.; Welch, C. J.; Schuster, D. I. Tetrahedron 1996, 52, 5131-5142. 